\title{
L. Leventhal-Belfer: Why do I have to? A Book for Children Who Find Themselves Frustrated by Everyday Rules
}

\author{
Jessica Kingsley Publishers, London, UK, 2008, 79 pp, ISBN 978-1-84310-891-7. \$9.95 \\ (paper)
}

\author{
Sarah Kuriakose
}

Published online: 28 July 2009

(c) The Author(s) 2009. This article is published with open access at Springerlink.com

Laurie Leventhal-Belfer's Why do I have to? is a thoughtfully structured guide for children who are frustrated with everyday rules and adults who are frustrated with those children. This short book is packed with a comprehensive set of questions, phrased from a child's perspective, dealing primarily with social expectations. The questions are broken down into sections dealing with home, with friends, and with school. The author addresses these questions by first validating the child's frustration, providing an answer, suggesting solutions, affirming the child, and inviting the child to add their ideas. Each question is accented with simple before and after illustrations related to following the rule.

The words "autism" and "Asperger's", or indeed any other technical jargon, are left completely out of the book. However, the rigidity and limited flexibility of many children on the spectrum is likely to be effectively targeted using this book. The writing level is suited for grade schoolers and adolescents. The author's use of a consistent structure throughout the book will be helpful to its target audience as children are able to predict what is coming next and brainstorm their own solutions.

Sections like, "Why do I have to let other kids play a game the "wrong way'?", "Why do I have to ask my teacher if it is OK to leave the room?", and "Why do I have to rest when I'm not tired?" will be familiar to many children, parents, and professionals. The questions speak to the magnitude of the author's clinical experience,

S. Kuriakose $(\square)$

Koegel Autism Center, University of California, Santa Barbara, Phelps Hall, Santa Barbara, CA 93106, USA

e-mail: skuriakose@education.ucsb.edu as do the evidence-based and clinically tested suggestions she offers for the child. For example, suggestions for the child who doesn't like asking the teacher for permission to leave the room include, "Ask the teacher the best ways to tell them when I need to leave the room, ask the teacher if I can use a card for those times when it's very hard for me to talk, choose a 'safe place' with my teacher where I can go when I need some quiet time to cool down if I get upset" (61). Solutions incorporate choices, replacement behaviors, sensory techniques, informal functional analyses, self-talk, reward charts, timers, and other tools that are successful for children with autism and Asperger's.

The book falls short in the clarity of some of the answers provided to its readers. While they are generally clear, some devolve into you-have-to-follow-the-rulesbecause-you-have-to logic, which will add to the frustration of some children. At times, the writing switches perspectives rapidly in order to help the child better understand the feelings of others involved. For example, in response to "Why do I have to go to a friend's house when I would rather stay home?", the author writes, "It can be very hard to leave your house to go visit a friend when you are in the middle of doing something you enjoy at home. You might have been frustrated when you had a play date set up, but your friend couldn't make it. It might help to remember the times that you had fun playing with other kids at their houses or at the park" (40). Unfortunately, this makes some of the answers unclear and may add to rigidity in children who have difficulty thinking from others' points of view. However, most of the answers will satisfy the majority of children, and the setup of the book as well as the introduction makes it clear that the guide is meant to be adapted for each child's success. 
This book will be an invaluable addition to the shelves for children who are challenged by the expectations of daily living. The insightful questions, thoughtful answers, and clinically tested suggestions will decrease frustration for children and parents alike.
Open Access This article is distributed under the terms of the Creative Commons Attribution Noncommercial License which permits any noncommercial use, distribution, and reproduction in any medium, provided the original author(s) and source are credited. 